\title{
European respiratory society international congress 2017: insights from the paediatric assembly
}

\author{
Raffaella Nenna, Laura Petrarca \\ Department of Paediatrics "Sapienza" University of Rome, Rome, Italy \\ Correspondence to: Dott. Raffaella Nenna. Department of Paediatrics, "Sapienza” University of Rome, V.le Regina Elena 324, 00161, Rome, Italy. \\ Email: raffaella.nenna@uniroma1.it.
}

Submitted Sep 05, 2017. Accepted for publication Oct 11, 2017.

doi: $10.21037 /$ jtd.2017.11.35

View this article at: http://dx.doi.org/10.21037/jtd.2017.11.35

The ERS International Congress 2017 featured interesting research results in Paediatric respiratory diseases. In particular a focus has been posed on factors predisposing to asthma and respiratory infections.

\section{Subclinical small-airway dysfunction precedes the development of asthma in children with allergic rhinitis}

Allergic rhinitis is frequently present in patients with asthma $(15-38 \%)$ and is consider a risk factor for the occurrence of the disease (1).

The mechanism underlying predisposing influence of allergic rhinitis on childhood asthma remains unknown. Fouzas et al. (2) investigated the pulmonary function in 73 children, at 6 years of age suffering from allergic rhinitis. They found that those who presented subclinical small-airway dysfunction measured with the forced oscillation technique (defined as $>30 \%$ decrease in Rrs or $>50 \%$ increase in Xrs after salbutamol administration, in asymptomatic children with normal baseline spirometry) during rhinitis exacerbation had a hazard ratio of 9.4 to develop asthma after an average period of $3.5 \pm 1.1$ years of follow-up. The authors concluded that the measurement of respiratory impedance during allergic rhinitis exacerbation could reveal children at risk of developing asthma and could be a useful tool for planning an adequate follow-up.

\section{Nasal cavity inflammation in patients with primary ciliary dyskinesia (PCD) is associated with bacterial infection}

Patients with PCD frequently suffer from rhinosinusitis symptoms.

It has been estimated that chronic rhinosinusitis affects over $50 \%$ of patients with PCD (3), often caused by inflammation and swelling of the nasal mucosa that can obstruct the sinus ostia (4).

Shoemark et al. (5) found that PCD patients had increased levels of inflammatory cytokines in nasal samples, compared to patients with cystic fibrosis and controls. In particular, PCD patients had significantly higher levels of IL-1 $\beta$, IL-2, IL-6, IL$10, \mathrm{TNF}-\alpha$ and IFN $\gamma$ than patients with $\mathrm{CF}$ and significantly higher levels of IL-6, IL-8, IL- $1 \beta$ and TNF- $\alpha$ than controls. In particular, $50 \%$ of $\mathrm{PCD}$ patients had a positive bacterial culture from nasal samples and higher levels of IL-6, IL- $1 \beta$ and TNF- $\alpha$ than PCD patients with negative culture.

\section{Early-life respiratory tract infections and the risk of lower lung function and asthma: a meta- analysis of 154,492 children}

Among the factors that could affect lung function and the development of asthma later in life are early respiratory tract infections. In particular, it has been demonstrated that pneumonia in early childhood is associated with impaired lung function in adulthood (6).

In the study of van Meel et al. (7) more than 150,000 children from 37 birth cohorts performed a five years followup and described an association between respiratory tract infections and asthma in later life (odds ratio for upper respiratory tract infection ranging from 1.25 to 1.56 , and for lower respiratory tract infection ranging from 2.00 to 3.72). Early life lower respiratory tract infections (but not upper) were associated with decreased lung function. 


\section{Acknowledgements}

None.

\section{Footnote}

Conflicts of Interest: The authors have no conflicts of interest to declare.

\section{References}

1. Leynaert B, Bousquet J, Neukirch C, et al. Perennial rhinitis: an independent risk factor for asthma in nonatopic subjects: results from the European Community Respiratory Health Survey. J Allergy Clin Immunol 1999;104:301-4.

2. Fouzas S, Skylogianni E, Triga $M$ et al. Subclinical small-airway dysfunction precedes the development of asthma in children with allergic rhinitis. Eur Respir J

Cite this article as: Nenna R, Petrarca L. European respiratory society international congress 2017: insights from the paediatric assembly. J Thorac Dis 2017;9(Suppl 16):S1557-S1558. doi: $10.21037 /$ jtd.2017.11.35
2017:50:OA3445.

3. Campbell R. Managing upper respiratory tract complications of primary ciliary dyskinesia in children. Curr Opin Allergy Clin Immunol 2012;12:32-8.

4. Tint D, Kubala S, Toskala E. Risk Factors and Comorbidities in Chronic Rhinosinusitis. Curr Allergy Asthma Rep 2016;16:16.

5. Shoemark A, Frost E, Harman K, et al. Nasal cavity inflammation in patients with primary ciliary dyskinesia (PCD) is associated with bacterial infection. Eur Respir J 2017;50:OA4627.

6. Chan JY, Stern DA, Guerra S, et al. Pneumonia in Childhood and Impaired Lung Function in Adults: A Longitudinal Study. Pediatrics 2015;135:607-16.

7. van Meel ER, Den Dekker H, Singh Ahluwalia S, et al. Early-life respiratory tract infections and the risk of lower lung function and asthma: a meta-analysis of 154,492 children. Eur Respir J 2017;50:OA499. 